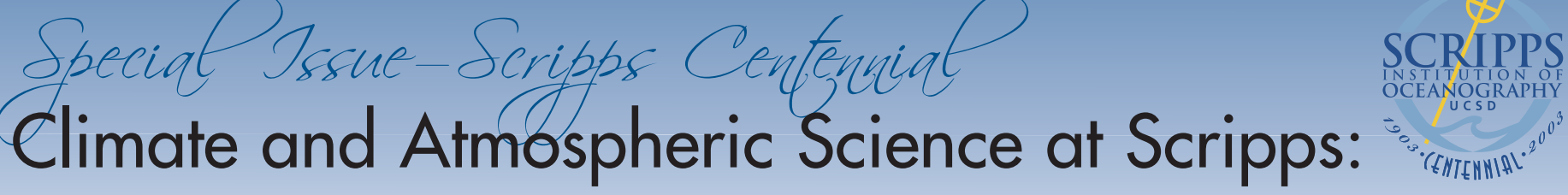 The Legacy of Jerome Namias
}

\author{
Richard C.J. Somerville \\ Scripps Institution of Oceanography, University of California • San Diego, California USA
}

Jerome Namias (1910-1997) pioneered the art and science of long-range weather forecasting. He also set off the modern era of research in climate and atmospheric science at Scripps Institution of Oceanography. Largely self-taught, Namias developed an exceptional physical intuition for the intricate interplay between atmosphere and ocean. In an era when the skill of weather forecasts was limited to two or three days, Namias advocated the heretical notion that climate, the sum total of weather, might be predictable for weeks, months, or even longer. He was among the first to realize that planetary-scale air-sea interactions strongly influence climate variability and thereby make certain, specialized types of predictions possible far beyond the time horizon of ordinary weather forecasts.

Namias's greatest strength as a scientist was his ability to develop profound insights by analyzing enormous amounts of observational data. His data included measurements of conventional meteorological variables such as winds, air temperatures, and atmospheric pressures, as well as measurements of oceanographic parameters, especially sea-surface temperatures. Throughout most of his long career, Namias's office walls were covered with maps and charts of these data, covering huge areas, typically much of the Northern Hemisphere. From this empirical material, Namias was able to infer mechanistic interconnections between air and sea, between phenomena in one part of the world and those in another, and between the evolution of these fields in the recent past and their probable course in the future (Figure 1).

\section{Global Climate at the Local Level}

Although his scientific interests were wide ranging, Namias was a synoptic meteorologist at heart; that is to say, a scientist interested in understanding and predicting the large-scale features of atmospheric circulation. Synoptic meteorology deals with aspects of the atmosphere that can be revealed by simultaneous measurements made throughout the earth by a global observing system. By international agreement, such a system has actually been in place for many decades. This system provides the raw data to satisfy the daily computational needs of operational weather prediction. It is these data that depict the continental-scale highs and lows gliding over the surface of the earth.

Even during the darkest periods of the Cold War, nations that could agree on little else continued to exchange weather data. The atmosphere does not heed national borders, so a storm over Siberia today may produce heavy snow in Chicago within a few days. Weather forecasting is far too important economically to be held hostage to politics. Climate research has benefited enormously from the immense archive of weather data extending back into the nineteenth century. This archive must be among the largest data sets in all of science. Namias's work relied entirely on this long-term monitoring of the state of the global atmosphere, paid for by the massive data requirements of weather prediction, and available essentially at no cost to climate researchers.

For many years at Scripps, Namias routinely issued forecasts of how the climate in the season to come might be expected to differ from the climatological average. Namias was interested in the big picture, not in local details. He was one of the first to appreciate the concept of teleconnections, a term connoting the ability of climate phenomena in one region of the earth to influence other regions thousands of miles away. An early form of these forecasts was a series of maps of the United States colored to show areas where average temperature and precipitation were predicted to be above normal, near normal, or below normal. For many years, Namias's winter predictions were presented to the public with considerable fanfare at a press conference held annually in early December. A certain degree of theatrical suspense inevitably accompanied the media treatment of perfectly natural questions, such as "When will the current drought end?" Namias clearly relished his starring role in these productions.

In hindsight, these seasonal predictions were often marred by significant errors. Nevertheless, Namias's verbal explanations, detailing how and why the largescale patterns of atmospheric circulation could be expected to evolve, were always fascinating and insightful, to both scientists and the media as well as to the public. The same was true of his explanations after the fact of why a given forecast had been right or wrong. For Namias, a failed forecast was just a learning opportunity. 


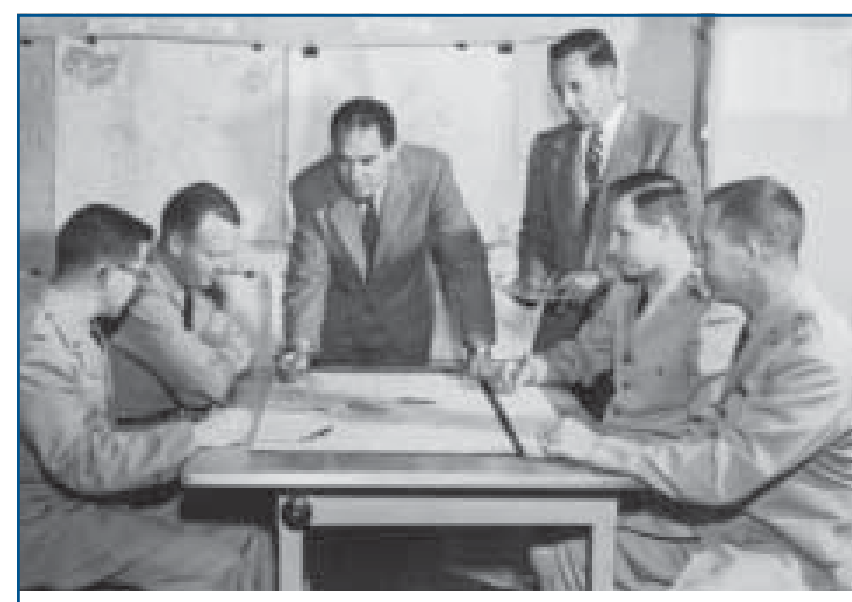

Figure 1. Jerome Namias (center) at Scripps in the early days.

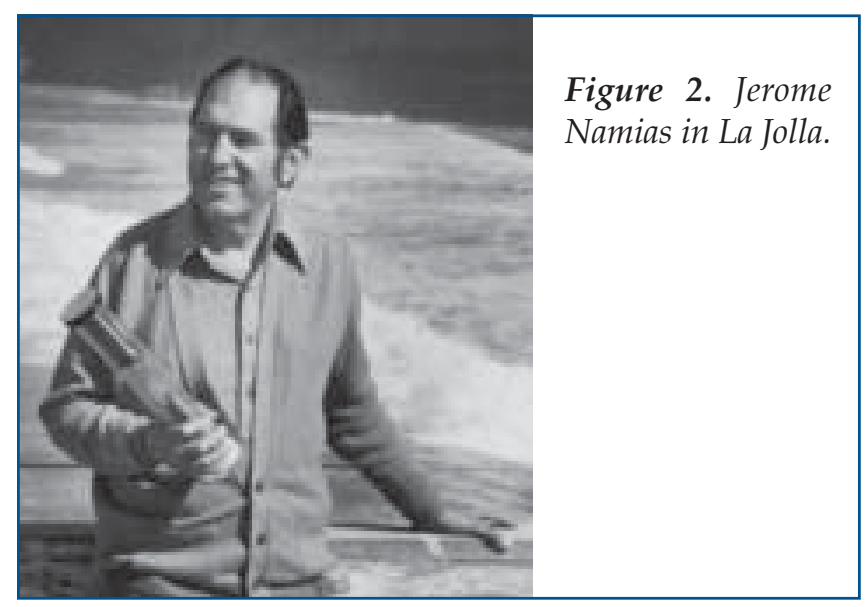

There is no doubt that part of the widespread popular appeal of climate prediction is its ambitious nature and global scale. The very idea that an immense and unusually warm sector of the Pacific Ocean in the fall season, for example, could somehow lead to a change in atmospheric circulation that in turn could produce an unusual pattern of precipitation over North America the following winter is inherently fascinating. In describing the continuous drama taking place in the atmosphere and ocean, Namias's fertile mind saw the action as playing out on a truly global stage.

For his seasonal predictions, Namias relied on methods that were not technically sophisticated and were often surprisingly subjective. Mathematically, his toolbox was mainly limited to simple statistical techniques that could show how the space-time patterns of various climate variables were correlated with one another. In fact, Namias took pride in making forecasts subjectively, based on insight, analogy to past events, and qualitative physical reasoning, and he often regarded numerical simulations of climate as his competition.

Throughout his career, Namias was openly disdainful of what he perceived as a tendency in some mathematical modelers to lose themselves in their tech- nology and to ignore empiricism. He also had little sympathy for purely statistical approaches to forecasting. Always courteous, he was nevertheless fond of pointing out unrealistic features of numerical climate model results and suggesting gently that "the kids with the computers" needed to rethink their equations. Namias respected the power of computational methods but inevitably viewed them as adjuncts to human forecasters and never as replacements for physical thinking.

Namias was far ahead of his time in identifying and recognizing the importance of many new concepts and phenomena in atmospheric science. He was also a prolific and instructive author, and the numerous case studies he analyzed and published are well worth studying today. Although Namias himself loved forecasting and was intellectually addicted to it, the insights displayed in his observational analyses are of more lasting scientific value than the successes and failures of his individual predictions.

In fact, the seasonal forecasts themselves, particularly the more successful ones, may best be regarded as constituting an unusual kind of challenge to Namias's more theoretically inclined colleagues. They represent a special type of existence proof: If Namias could study a wall full of maps of observational data and thereby produce a skillful seasonal forecast, then surely it ought to be possible to construct a mathematical model to make such a climate forecast deductively and objectively, preferably from first principles-in the same sense that the existence of human chess grandmasters is a challenge to people who build chess-playing computer programs.

In climate research, as in chess, computer programs have greatly improved in recent years. Unlike chess, however, climate is a subject whose scope rapidly expands as time goes on. Therefore, today we seek to develop models that can not only predict the next El Niño, but can also foretell how increasing amounts of atmospheric carbon dioxide will change the climate of the coming century (Figure 2).

\section{An Unconventional Biography}

For a first-rank scientist, Namias had an unconventional biography. He was a weather enthusiast from childhood. Illnesses and economic difficulties in his youth kept him from pursuing a conventional educational and career path. Instead, he took correspondence courses, read voraciously, held a variety of jobs, and benefited from personal contacts with leading scientists of the time, whom he actively sought out after studying their papers. Although Namias eventually received honorary doctorates and many other awards, his only earned degree was a master's from the Massachusetts Institute of Technology (MIT), which he received at the age of 31. Namias is surely unusual and perhaps unique among members of the National Academy of Sciences in that he earned neither an undergraduate university degree nor a Ph.D. 
As a graduate student at MIT in the early months of World War II, Namias was involved in a project investigating the feasibility of longrange weather forecasts. At the time, "long range" meant five days, and conventional wisdom was that skillful forecasts at such a range were impossible. Nevertheless, the potential military importance of such forecasts was enormous, and Namias took leave from MIT to go to Washington to lead a project pursuing this topic. During the war, he made predictions, did research, and trained military and civilian weather personnel. For the next three decades, he headed the long-range forecasting effort of the U.S. Weather Bureau, later called the National Weather Service, and now a part of the National Oceanic and Atmospheric Administration (NOAA).

\section{Namias at Scripps Institution of Oceanography}

Namias's involvement with Scripps began with a celebrated conference in 1957 in Rancho Santa $\mathrm{Fe}$, California, a wealthy residential enclave located several miles north of the Scripps campus in La Jolla. The conference had been called to discuss an unusual state of events occurring in the atmosphere and ocean, with disruptive effects on marine life and fisheries. Today even children know the name for this phenomenon: El Niño.

In 1957, however, that name was associated with a local oceanographic event off the coast of Peru, and the global scale and major climatological significance of the El Niño phenomenon were entirely unknown to science. At the Rancho Santa Fe conference, Namias found interest in his ideas on large-scale interactions between the atmosphere and the ocean. He held discussions with many scientists, including John Isaacs and Walter Munk of Scripps.

These contacts continued in the ensuing years. Beginning in 1968, Namias held an appointment on the Scripps research staff. In 1971, after several long-term visits to La Jolla, he formally retired from NOAA and moved permanently to Scripps. Although Namias was then more than 60 years old, he was not at all interested in retirement. Instead, he embarked on a second career. Indeed, he published about the same number of papers after coming to Scripps as he had before (Roads, 1998).

Scripps had a strong influence on Namias, and he enjoyed scientific discussions with oceanographers, biologists, geologists, and others with interests overlapping his own. Large-scale air-sea interactions dominated his research for the remainder of his career. At the same time, Namias's high-profile presence clearly changed the evolution of Scripps. William A.

Nierenberg, then the director of the institution, together with many other Scripps leaders, eventually became convinced that climate, broadly interpreted, was an interdisciplinary and unifying theme that should play an important role in the future of Scripps.

Nierenberg once remarked that he gradually came to regard climate as one of the main intellectual and practical justifications for oceanographic research. Whatever the reasoning, Scripps collectively decided that atmospheric science deserved a prominent place at the institution. Adding atmospheric science was a logical step in the evolution of Scripps, which had begun as a small marine biological field station and was destined to become a large and wide-ranging earth science institution. Nierenberg's successors, Edward A. Frieman and Charles F. Kennel, have both endorsed this commitment to climate as a major theme for Scripps, and to atmospheric science as an essential component of climate research. Thus, the Climate Research Group that had formed around Namias, and that was focused on seasonal predictions and other topics dear to his heart, was identified as a target for growth.

By the end of the 1970s, scientists in the group, in addition to Namias, included Tim Barnett, Dan Cayan, John Roads, and myself. Individual research interests ranged from atmospheric predictability theory to physical oceanography. However, all were also interested in the seasonal forecasting problem, or more generally, in understanding short-term climate variability. Together, we were successful in winning a nationwide competition to form the first Experimental Climate Prediction Center (ECPC). The formation of such centers, funded by NOAA, had been authorized by an act of the U.S. Congress in 1978 establishing the National Climate Program.

There is no doubt that Namias's reputation was a key reason for NOAA's decision to locate the first ECPC at Scripps. This center, which continues today, headed by Roads, has been a fruitful source of research results, many of which have been used in operational 
practice by NOAA. In particular, Barnett did early pioneering research on analogue techniques as well as on statistical methods for short-period climate forecasting. For many years, Barnett and Namias carried on a more-or-less friendly internal competition as to whose approach led to the better predictions. Most important, they both learned from one another (Figure 3).

In the 1980s, the Climate Research Group grew in numbers and broadened its scientific interests. The new arrivals brought expertise in meteorology, oceanography, hydrology, numerical modeling, and other disciplines. Young scientists fresh from graduate school arrived to begin their research careers, including atmospheric modeler Shyh-Chin Chen and theoretical oceanographer Arthur Miller. Several members of the group developed new research programs related to longer time-scale climate variability, including aspects of the decade-to-century time scale issues centered around anthropogenic climate change. These topics continue to engage the group today and range from fundamental studies of the role of clouds in the climate system to more applied work on predicting regional aspects of climate change.

At the same time, the formation of the California Space Institute (CalSpace), a multicampus University of California research group headquartered at University of California, San Diego, provided an impetus at Scripps for satellite remote-sensing research on climate. Under its founding director, cosmochemist James Arnold, and his successor, physicist and former astronaut Sally Ride, CalSpace devoted resources to studies of climate from space. One result was to add scientists to the Scripps research staff with expertise in topics such as radiative transfer theory and remote sensing.

With the exception of space-based observations, however, the climate and atmospheric science work at Scripps throughout the 1980s was mainly devoted to theory, modeling, and diagnostic analysis of conventional meteorological and oceanographic data. One important aspect of research that was conspicuously missing at Scripps was in direct observations; none of the scientists in the Climate Research Group actually made measurements of any kind. Instead, the group continued to rely heavily on observational data gathered globally by the weather services of many countries for the purpose of making daily weather forecasts. Indeed, Namias once remarked, commenting on a photograph of himself standing on the Scripps pier and holding a bathythermograph, that if his friend who had invented the instrument could see Namias holding it, he "would be pleased, or amazed" (Namias, 1986).

\section{Scripps After Namias}

In November 1989, Namias suffered a stroke, which abruptly ended his research career. The stroke left him partially paralyzed and unable to work. He remained in La Jolla and lived for more than seven years after the stroke. During that time, he was alert and appeared far younger than his age, and he enjoyed visits from his scientific colleagues with obvious relish. However, he never regained the ability to speak or write.

One of the secrets to Namias's extraordinarily productivity and versatility as a scientist was that he resolutely avoided distractions from research. He disliked administrative tasks and proposal writing, perhaps because he'd had to do so much of both in his earlier career with the Weather Bureau. Over time, he became adept at inducing his Scripps colleagues to help out with these tasks. One of Namias's charming oddities was that he never bothered to learn to drive. Somehow, whenever he needed personal transportation, someone from Scripps always appeared with a car.

Namias was so single-mindedly devoted to his research that during his time at Scripps, he never taught a course and never advised a graduate student. He had taught meteorology to large numbers of students during and after World War II, and he lectured extensively around the world before and after coming to Scripps. He would talk science enthusiastically with anybody at any time. However, he chose not to participate formally in the academic side of Scripps, which is a university graduate department as well as a research institution.

After coming to Scripps in 1979, I taught the institution's first courses in atmospheric science, and the first graduate students in the field arrived soon after. The size of the atmospheric science faculty doubled in 1990 when Veerabhadran Ramanathan arrived. It has subsequently grown further, with the addition of Paul Crutzen, Joel Norris, and Lynn Russell.

A new branch of the Scripps Graduate Department, the Climate Sciences Curricular Group, was created in 1995. In addition to the atmospheric science faculty, the group includes geochemists, paleoclimatologists, physical oceanographers, and other members of the Scripps faculty interested in climate-related topics. This group provides an interdisciplinary curriculum for graduate students pursuing a wide range of climate interests. Several members of the Scripps research staff also teach UCSD undergraduates, advise Ph.D. dissertation research and financially support graduate students via research grants.

Organizational changes have also occurred on the research side of Scripps in the post-Namias era. The Climate Research Group that he founded was elevated to higher status in 1989, becoming the Climate Research Division (CRD). I headed the unit from 1979 to 1996, and Cayan has directed it since. Ramanathan and several colleagues formed a new research center, the Center for Atmospheric Science (CAS). Ramanathan also succeeded in attracting decade-long funding from the National Science Foundation in the form of support for a science and technology center, the Center for Clouds, Chemistry, and Climate. Like Namias before him, Ramanathan received the highest research award of the American Meteorological Society and was elected to the National Academy of Sciences, among many other honors. 


\section{Climate Science in the Twenty-First Century}

In the more than three decades since Namias joined Scripps, profound changes have occurred in the way research is carried out in climate and atmospheric science. The roles of satellites and computers have become central. Concerns about climate changes due to human influences have pushed the science into the forefront of public concerns and policy debates. The range of topics pursued by climate researchers has expanded immensely. The effort at Scripps that was originally confined to large-scale air-sea interactions has now evolved into a broad spectrum of research.

Topics recently under investigation in CAS and CRD include the following:

- detection of climate changes unlikely to be within the range of normal variability and the attribution of these changes to specific causes,

- modeling of regional and transient aspects of climate change specific to California and the West,

- development and testing of coupled oceanatmosphere models for predicting the El NiñoSouthern Oscillation and related phenomena;

- diagnostic analysis of surface and space-based measurements of global cloud properties,

- studies of the physical and chemical properties of atmospheric aerosols and their roles in the climate system, and

- interpretation of satellite observations of climate phenomena in the Arctic and Antarctic.

We have come a long way from the original focus on seasonal forecasts.

The individual, curiosity-driven research typical of climate science in Namias's era has certainly not disappeared, but it has been supplemented by large, multiinvestigator efforts in modeling and observations. Many scientists from CRD and CAS participate in major national and international collaborative programs, such as the Atmospheric Radiation Measurement (ARM) Program of the U.S. Department of Energy. ARM is dedicated to achieving a greater understanding of the role of clouds and cloud-radiative feedbacks in the climate system. Ramanathan reinvented himself as a researcher after joining Scripps. Originally a theorist and modeler, he later did creative research on the interpretation of satellite measurements of the earth's radiation budget. At Scripps, he has become an ardent maker of observations. In particular, he has helped to fill the observational void in atmospheric science and climate at Scripps by playing key roles in a series of major field-observation programs.

The first of these programs was the 1993 Central Equatorial Pacific Experiment (CEPEX), conceived to explore cloud-radiation interactions observationally. Subsequently, Ramanathan was cochief scientist of the Indian Ocean Experiment (INDOEX), a major international project centered around an intensive field phase in early 1999 involving aircraft, ships, surface stations, and more than 150 scientists. INDOEX was outstandingly successful in documenting the role of aerosols (small haze particles in the atmosphere) as important contributors to climate change. One intriguing INDOEX result has been to establish that aerosols can provide either local heating via absorption of sunlight or local cooling via scattering of sunlight, depending on circumstances. Another has been to show that aerosols originating in the Indian Ocean and Asian regions can be transported by wind across the Pacific and affect North America.

The other cochief scientist of INDOEX was Paul Crutzen, a member of CAS, one of the world's foremost atmospheric chemists, and the first Nobel laureate at Scripps. Crutzen shared the 1995 Nobel Prize in chemistry for his pioneering work on atmospheric ozone. He had been among the first to show that a variety of human activities might damage the earth's protective ozone layer by leading to chemical reactions that would decrease the amount of stratospheric ozone.

Recently, Crutzen, Ramanathan, and colleagues have begun a more extensive effort than INDOEX. The Asian Brown Cloud $(A B C)$ project will investigate the pervasive haze found over much of Asia. It is already clear that atmospheric pollution in the form of aerosols can affect clouds, precipitation, human health, and climate over large portions of the surface of the earth.

Field programs such as INDOEX and $A B C$ are far more extensive spatially than more localized studies such as ARM and CEPEX. However, even these large programs are dwarfed in scale by a planned effort at Scripps. Francisco Valero of CAS, a renowned expert in measuring solar and terrestrial radiation from the surface of the earth, from airplanes, and from orbiting satellites, has now undertaken the most ambitious project of his career. This will be the first deep-space mission to look back at planet Earth. If all goes well, Valero's instruments will be parked at L1, the Lagrange point where Earth's gravitational attraction is nearly balanced by that of the sun. From this point, about a million miles from Earth, remote sensing is truly remote, and a telescope aboard the spacecraft will continually view the passage of weather systems across the full sunlit side of Earth. Valero's mission will produce continual real-time images of the atmosphere in motion.

Namias, who always sought the big picture, the bold hypothesis, and the comprehensive global view, would no doubt have been delighted.

\section{References}

Namias, J., 1986: Autobiography. Namias Symposium [Scripps Institution of Oceanography Reference Series 86-17, pp. 3-36].

Roads, J.O., 1998: Jerome Namias. Biographical Memoirs, v. 76, National Academy of Sciences, National Academy Press, Washington, DC. 